\title{
Measuring the dayside reconnection rate during an interval of due northward interplanetary magnetic field
}

\author{
G. Chisham ${ }^{1}$, M. P. Freeman ${ }^{1}$, I. J. Coleman ${ }^{1}$, M. Pinnock ${ }^{1}$, M. R. Hairston ${ }^{2}$, M. Lester ${ }^{3}$, and G. Sofko ${ }^{4}$ \\ ${ }^{1}$ British Antarctic Survey, Natural Environment Research Council, High Cross, Madingley Road, Cambridge, CB3 0ET, UK \\ ${ }^{2}$ Center for Space Sciences, The University of Texas at Dallas, Richardson, Texas, USA \\ ${ }^{3}$ Department of Physics and Astronomy, University of Leicester, Leicester, LE1 7RH, UK \\ ${ }^{4}$ Institute of Space and Atmospheric Studies, University of Saskatchewan, Saskatoon, Saskatchewan, Canada
}

Received: 2 June 2004 - Revised: 13 September 2004 - Accepted: 6 October 2004 - Published: 22 December 2004

\begin{abstract}
This study presents, for the first time, detailed spatiotemporal measurements of the reconnection electric field in the Northern Hemisphere ionosphere during an extended interval of northward interplanetary magnetic field. Global convection mapping using the SuperDARN HF radar network provides global estimates of the convection electric field in the northern polar ionosphere. These are combined with measurements of the ionospheric footprint of the reconnection X-line to determine the spatiotemporal variation of the reconnection electric field along the whole $\mathrm{X}$-line. The shape of the spatial variation is stable throughout the interval, although its magnitude does change with time. Consequently, the total reconnection potential along the $\mathrm{X}$-line is temporally variable but its typical magnitude is consistent with the cross-polar cap potential measured by low-altitude satellite overpasses. The reconnection measurements are mapped out from the ionosphere along Tsyganenko model magnetic field lines to determine the most likely reconnection location on the lobe magnetopause. The X-line length on the lobe magnetopause is estimated to be $\sim 6-11 R_{E}$ in extent, depending on the assumptions made when determining the length of the ionospheric X-line. The reconnection electric field on the lobe magnetopause is estimated to be $\sim 0.2 \mathrm{mV} / \mathrm{m}$ in the peak reconnection region.
\end{abstract}

Key words. Space plasma physics (Magnetic reconnection) - Magnetospheric physics (Magnetopause, cusp and boundary layers) - Ionosphere (Plasma convection)

\section{Introduction}

Magnetic reconnection represents the major process whereby energy, momentum, and plasma are transferred from the solar wind into the magnetospheric system. The topology of the reconnection scenario, and the extent of the Earth's magnetopause over which reconnection occurs, vary greatly with

Correspondence to: G. Chisham

(g.chisham@bas.ac.uk) the orientation of the prevailing interplanetary magnetic field (IMF). Under conditions of southward IMF $\left(B_{z}<0\right)$, reconnection is thought to occur predominantly on low-latitude regions of the magnetopause between the Northern and Southern Hemisphere cusp regions. Under these conditions, IMF field lines in the magnetosheath reconnect with closed magnetospheric magnetic field lines to generate new open geomagnetic flux. Under conditions of northward IMF $\left(B_{z}>0\right)$, reconnection is thought to occur between the IMF in the magnetosheath and open tail lobe geomagnetic field lines on the high-latitude magnetopause tailward of the cusps (Dungey, 1963).

The existence of high-latitude "lobe" reconnection during northward IMF conditions has been verified by in-situ spacecraft observations of mixed populations of accelerated magnetosheath and magnetospheric plasma close to the magnetopause (Gosling et al., 1991; Kessel et al., 1996), and by the observation of reconnection-associated plasma jets at the high-latitude magnetopause (Phan et al., 2003). Further evidence of lobe reconnection is often seen in low-altitude spacecraft measurements of particle precipitation. These observations often show a "reverse" cusp ion dispersion signature under northward IMF conditions, whereby the observed energy of precipitating magnetosheath-like ions in the cusp decreases with decreasing invariant latitude (Burch et al., 1980; Woch and Lundin, 1992; Matsuoka et al., 1996), in the opposite sense to that observed in the cusp during southward IMF conditions. This is a direct result of the energy dispersion of the particles during their time-of-flight, otherwise known as the velocity filter effect, resulting in particles precipitating at different latitudes as the newly-reconnected field lines convect sunward following reconnection (Onsager et al., 2001).

However, much of the observational evidence for lobe reconnection comes from ionospheric observations that imply the existence of two "reverse" convection cells, as suggested by Dungey (1963) (termed "reverse" as their sense of rotation is opposite to that observed during southward IMF conditions). 

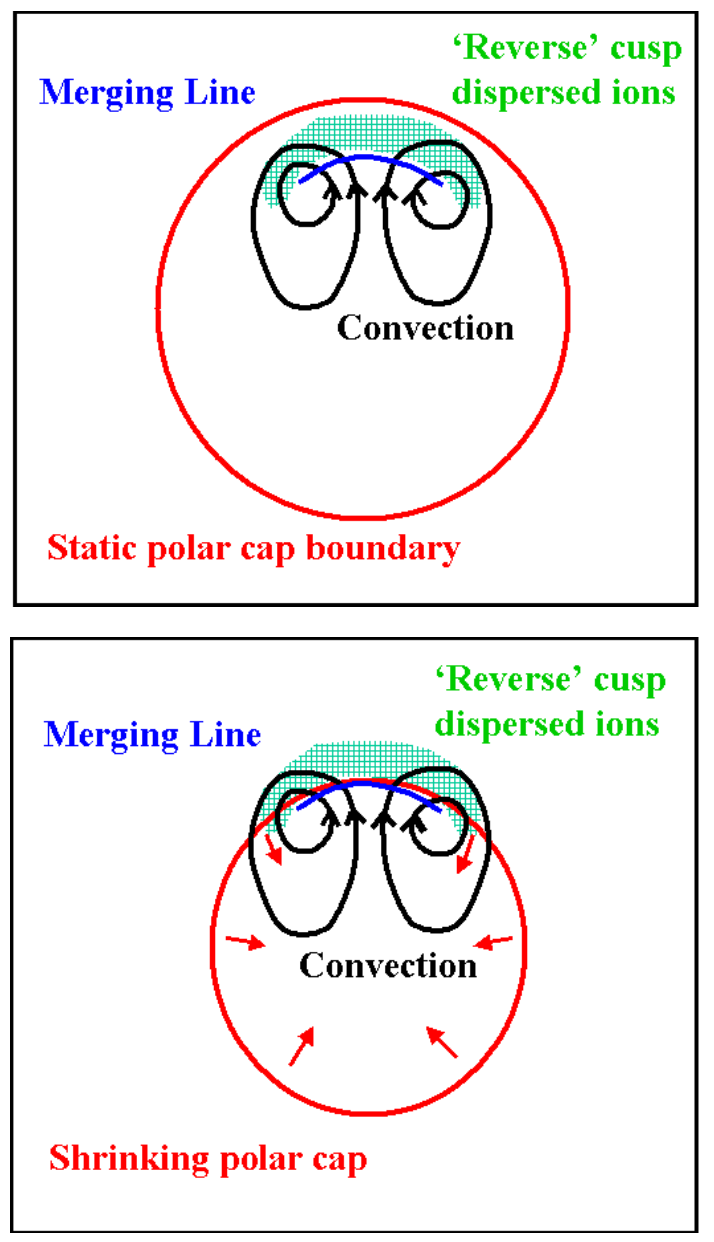

Fig. 1. Schematic diagrams showing the relationship between the polar cap boundary (red circle), the ionospheric projection of the merging line (blue arc), the reverse ionospheric convection cells (black curves), and the reverse cusp ion dispersion region (shaded green region) for two possible reconnection scenarios during an interval of northward IMF. (a) Reconnection on a particular magnetosheath field line occurs in one hemisphere only. (b) Reconnection on a particular magnetosheath field line occurs in both hemispheres simultaneously.

In this picture, plasma at the footprint of the reconnection $\mathrm{X}$-line convects sunward, due to the magnetic tension of the newly-reconnected field lines, before being swept antisunward towards dawn and dusk with the magnetosheath flow. Early observations of ionospheric flow during northward IMF conditions showed the existence of sunward convection within the polar cap ionosphere (Maezawa, 1976; Burke et al., 1979). Further observations illustrated that "four-cell" convection was typical during these conditions two reverse convection cells within the polar cap, with two "normal" convection cells, thought to be driven by viscous processes at the magnetopause, at lower latitudes (Heelis et al., 1986; Knipp et al., 1991; Freeman et al., 1993; Reiff and Heelis, 1994; Cumnock et al., 1995). Huang et al. (2000a) presented direct observations of complete reverse convection cells and showed that the four-cell convection was stable and persistent as long as the IMF was stable. However, the convection pattern that exists during times of northward IMF can often be difficult to characterise, due to the limited extent of the reverse convection cells and the small-scale structure that increases towards the nightside ionosphere.

In the original Dungey paradigm, reconnection occurs in both hemispheres on the same magnetosheath field line, leading to new closed flux in the dayside magnetosphere (Song and Russell, 1992; Sandholt et al., 2000). Russell (1972) noted, however, that tail lobe reconnection, and hence the resultant magnetospheric convection, could be confined to a single hemisphere. In this scenario, the effect of reconnection is to reconfigure open geomagnetic flux, rather than to transfer flux between the open and closed regions of the magnetosphere.

In Fig. 1 we present schematic diagrams which illustrate the typical steady-state ionospheric convection scenarios under northward IMF conditions (Sandholt et al., 2000). In this figure we show only the reverse convection cells that are driven by lobe reconnection, and not the lower latitude viscous-driven cells. The reverse cells are typically called "merging" cells if new closed flux is created, or "lobe" cells if open flux is merely circulated within the polar cap (Burch et al., 1985; Reiff and Burch, 1985). The figures are drawn assuming that the IMF $B_{y}$ component is small compared to the $B_{z}$ component, under which conditions the convection cells are symmetric and roughly equal in size. As the magnitude of the IMF $B_{y}$ component increases, one of these cells will start to dominate the convection and introduce asymmetry into the convection scenario (Russell, 1972; Heelis, 1984; Burch et al., 1985; Reiff and Burch, 1985).

Figure 1a illustrates the scenario which results from reconnection in one hemisphere only, when no new closed flux is created. The lobe convection cells are located wholly on open field lines within the polar cap (Burch et al., 1985; Reiff and Burch, 1985). No flux is either added to, or lost from, the polar cap and hence, there is no change in its size as a result of the lobe reconnection. In this scenario, the ionospheric projection of the merging line and the signature of the reverse cusp ion dispersion are located within the polar cap.

Figure $1 \mathrm{~b}$ presents the scenario which results from reconnection in both hemispheres on the same magnetosheath field line. Open flux is converted to closed flux and the convection flow streamlines in the merging cells cross the polar cap boundary. Flux is lost from the polar cap and hence, the polar cap shrinks. In this scenario, the ionospheric projection of the merging line is co-located with the polar cap boundary and the reverse cusp ion dispersion is located on closed field lines equatorward of this. Whereas these represent the basic scenarios that exist under northward IMF conditions, there have been a wide range of proposed reconnection topologies that might exist (Crooker, 1992; Onsager and Lockwood, 1997; Lockwood and Moen, 1999; Sandholt et al., 2000; Onsager et al., 2001), and typically, the scenarios can vary drastically in opposite hemispheres (in terms of both the reconnection rate and location). 
The relative likelihood of lobe reconnection in the two hemispheres is strongly controlled by the seasonal tilt of the magnetic dipole, favouring reconnection in the summer hemisphere (Crooker and Rich, 1993). Observations have shown that ionospheric convection is much less ordered in the winter polar cap than in the summer polar cap and that the reconnection potential is much reduced (Freeman et al., 1993). The magnitude and direction of the IMF $B_{x}$ component also has a large influence on this interhemispheric asymmetry. A large IMF $B_{x}$ component can alter the effective dipole tilt of the magnetosphere with respect to the IMF, and hence, alter the favoured hemisphere for reconnection (Lockwood and Moen, 1999).

Measurements of the reconnection electric field (or reconnection rate), and its variation along the reconnection $\mathrm{X}$-line can be made by identifying the ionospheric projection of the reconnection X-line and measuring the electric field tangential to it in its rest frame. The dayside reconnection electric field has been measured extensively in this way under southward IMF conditions (Baker et al., 1997; Pinnock et al., 1999; Blanchard et al., 2001; Milan et al., 2003; Pinnock et al., 2003), but measurements under northward IMF conditions have been generally confined to determinations of the cross-polar cap potential from low-altitude spacecraft overflights or from model convection patterns (Cumnock et al., 1995; Weimer, 1995; Ruohoniemi and Greenwald, 1996). Cumnock et al. (1995) measured a potential drop of $\sim 10-20 \mathrm{kV}$ between the centres of the reverse convection cells during intervals of northward IMF. By developing statistical models of electric field equipotentials based on DE-2 spacecraft data, Weimer (1995) determined that the potential drop varied from $\sim 10-30 \mathrm{kV}$ over the typical range of IMF field strengths and dipole tilt orientations. To date, there have been no direct measurements of the lobe reconnection electric field during northward IMF conditions.

In this study we use measurements from the Super Dual Auroral Radar Network (SuperDARN) (Greenwald et al., 1995) and the Defense Meteorological Satellite Program (DMSP) low-altitude spacecraft to study reconnection during an extended interval of northward IMF. First, we present an overview of the conditions which characterize the whole interval. Second, we take a sub-interval of data and directly measure the spatial and temporal variation of the reconnection electric field along the entire length of the X-line projected to the dayside ionosphere. Consequently, we determine the temporal variation of the reconnection potential during this sub-interval. We then map these results to the lobe magnetopause to estimate the extent of the merging line and the reconnection electric field at the in-situ X-line.

\section{Event overview}

On 11 November 1998, the IMF was characterised by an extended interval during which $B_{z}>0$ for over $12 \mathrm{~h}$. Figure 2 presents the three Geocentric Solar Magnetospheric (GSM) components of the IMF for the central part of this

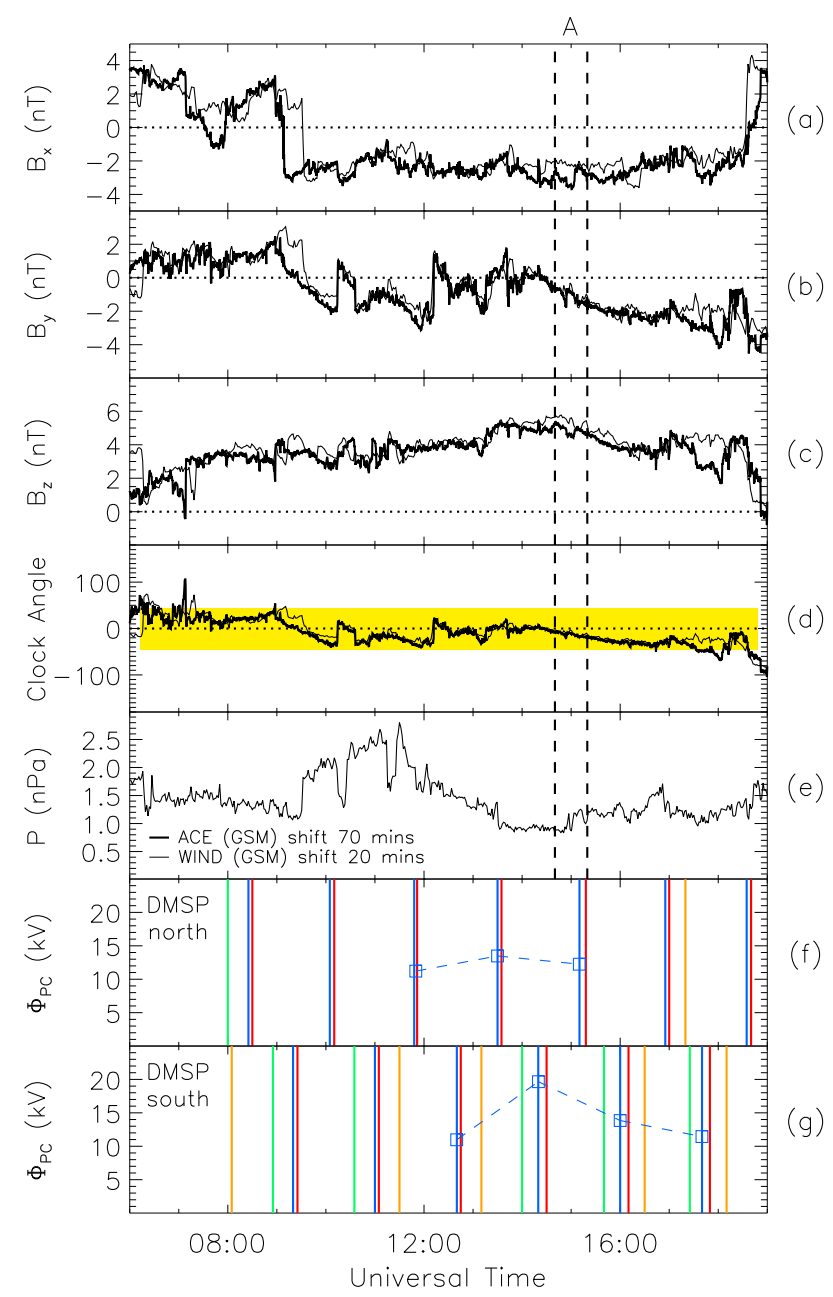

Fig. 2. The variation in IMF parameters (a) $B_{x}$, (b) $B_{y}$, (c) $B_{z}$, and (d) clock angle, between 06:00 and 19:00 UT on 11 November 1998. The bold lines represent the GSM variations measured by the ACE spacecraft, shifted by $70 \mathrm{~min}$. The thin lines represent the GSM variations measured by the WIND spacecraft, shifted by $20 \mathrm{~min}$. The yellow shaded region in panel (d) highlights the region between $-45^{\circ}$ and $45^{\circ}$ clock angle. Panel (e) presents the solar wind dynamic pressure measured by the WIND spacecraft, shifted by $20 \mathrm{~min}$. Panels (f) and (g) present the timings of DMSP overpasses of the Northern and Southern Hemisphere ionospheres, respectively. The passes are colour-coded as follows; DMSP-F11 (orange), DMSP-F12 (green), DMSP-F13 (blue), and DMSP-F14 (red). The blue squares joined by dashed lines present the potentials measured between the centres of the reverse convection cells by DMSP-F13 at these times. The vertical dashed lines in panels (a) to (e) delineate interval A, studied in detail in this paper (14:40 to $15: 20 \mathrm{UT}$ ).

day, as measured by the ACE (bold line) and WIND (thin line) spacecraft. ACE (located at $(220,-25,-12) R_{E}$ GSM) and WIND (located at $(46,17,-2) R_{E} \mathrm{GSM}$ ) observed very similar large-scale IMF variations, when shifted in time, despite their large separation. By assuming that these largescale IMF variations were plane waves, whose wave vector lay in the $x-y$ plane, and which convected at the solar wind 


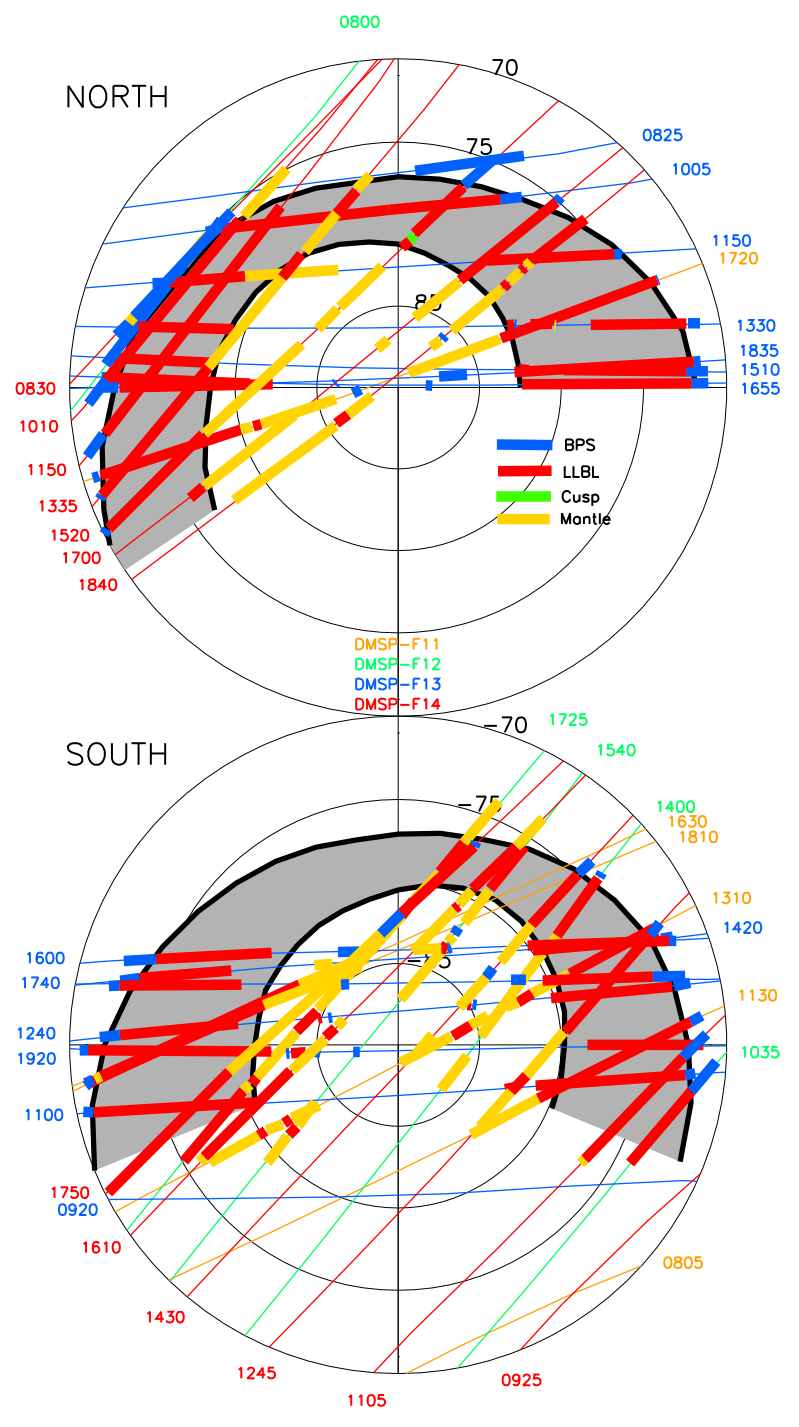

Fig. 3. The tracks of all the DMSP polar overpasses during the interval 08:00-19:00 UT on 11 November 1998, in both the Northern and Southern Hemispheres. The tracks (thin lines) and timings (located at one end of each track) are colour-coded as follows; DMSP-F11 (orange), DMSP-F12 (green), DMSP-F13 (blue), and DMSP-F14 (red). Overlaid as thick lines on the tracks are the locations of the BPS (blue), LLBL (red), cusp (green), and mantle (yellow) precipitation regions as determined by the Newell et al. (1991) algorithm. The grey-shaded regions represent approximate fits-by-eye to the LLBL precipitation regions.

velocity, the plane wave orientation could be estimated from the time shift between the two sets of observations. Hence, an estimate of the time delay of the IMF variations from the spacecraft to the magnetosphere could be determined. The data in Fig. 2 have been shifted accordingly to the time of the first magnetosphere encounter, by $20 \mathrm{~min}$ for WIND, and by 70 min for ACE.

Figure 2a presents the IMF $B_{x}$ component which remained steady at around -1 to $-3 \mathrm{nT}$ between 10:00 and 18:00 UT. Figure $2 \mathrm{~b}$ presents the IMF $B_{y}$ component, which changed from $\sim 2$ to $\sim-4 \mathrm{nT}$ across the interval. The IMF $B_{z}$ component, shown in Fig. 2c, was positive throughout the whole interval, reaching a peak of $\sim 5 \mathrm{nT}$. The dominance of the $B_{z}$ component during this interval is best shown by the clock angle variation in Fig. $2 \mathrm{~d}$ which remained between $45^{\circ}$ and $-45^{\circ}$ (as encompassed by the yellow shaded region) for almost all the interval. Hence, the IMF can be described as close to northward in the GSM $y-z$ plane, but tilted toward the Northern Hemisphere in the GSM $x-z$ plane.

This tilt in the $x-z$ plane has important implications when considering which hemisphere has the dominant lobe reconnection site. At this time of year (almost midway between equinox and Northern Hemisphere winter solstice), the dipole tilt of the magnetosphere would tend to favour the Southern (summer) Hemisphere lobe as the dominant reconnection site. However, the significant IMF $B_{x}$ component works to counter the effect of the dipole tilt and means that conditions in the Northern (winter) Hemisphere lobe are also favourable. Figure 2e presents the variation in the solar wind dynamic pressure measured by WIND. The pressure is relatively steady around $\sim 1.0-1.5 \mathrm{nPa}$, except for some excursions to $\sim 2.0-2.5 \mathrm{nPa}$ between 09:30 and 12:00 UT.

Variations in the size of the polar cap provide information about the level of flux transfer between open and closed geomagnetic field lines and hence, whether reconnection is resulting in new closed flux. We investigated variations in the size of the polar cap over this interval by studying particle precipitation data from the low-altitude DMSP spacecraft. The DMSP spacecraft are in near-polar Sunsynchronous orbits at altitudes of $\sim 840 \mathrm{~km}$ with orbital periods of $\sim 100 \mathrm{~min}$. The SSJ/4 detectors (Hardy et al., 1984) measure precipitating electrons and ions at 19 distinct energy levels, ranging from $32 \mathrm{eV}$ to $30 \mathrm{keV}$ in logarithmic steps and obtain a complete differential energy spectrum in $1 \mathrm{~s}$, which equates to an effective spatial resolution of $\sim 7 \mathrm{~km}$.

In this paper we use dayside precipitation regions automatically identified in the DMSP energy spectra using the logical rules outlined in Newell et al. (1991). During the interval presented in Fig. 2 there were 16 Northern Hemisphere and 22 Southern Hemisphere DMSP passes from which we could obtain particle precipitation data. The vertical lines in Figs. $2 \mathrm{f}$ and $2 \mathrm{~g}$ indicate the central times of these DMSP passes in the Northern and Southern Hemispheres, respectively. The different DMSP spacecraft are identified by colour; DMSP-F11 (orange), DMSP-F12 (green), DMSPF13 (blue), and DMSP-F14 (red).

In Fig. 3 we present the tracks of all the DMSP passes highlighted in Fig. 2, in both hemispheres, on Altitude Adjusted Corrected GeoMagnetic (AACGM) coordinate polar grids. Each pass (marked by a thin line), and its central universal time (highlighted at the end of each pass), are colourcoded to identify the spacecraft, as in Fig. 2. Plotted over the spacecraft tracks (thick lines) are the locations of the boundary plasma sheet (BPS) (blue), low-latitude boundary layer (LLBL)(red), cusp (green), and mantle (yellow) precipitation regions, as identified for each pass using the automatic algorithm of Newell et al. (1991). 
Even though the algorithm is not $100 \%$ reliable on a case to case basis, by and large the different precipitation regions appear well ordered and occupy distinct spatial regions that vary little with time. The grey-shaded regions in Fig. 3 represent an approximate fit by eye to the location of the LLBL precipitation region, where the lower limit matches the transition between the BPS and LLBL precipitation and the upper limit matches the transition between the LLBL and mantle precipitation. These limits are marked by the bold black lines at the edges of the grey-shaded region. Rarely, for all the DMSP passes in the whole 12-hour interval, do the precipitation boundaries move further than $1.0^{\circ}$ of latitude from the limits shown.

This suggests that the locations of the auroral precipitation regions remain quasi-stationary for most of the interval being studied. We use the quasi-stationary nature of the observations presented in Fig. 3 as a justification for assuming a quasi-stationary merging line (i.e. that the latitudinal motion of the merging line is generally small compared to the convection flow velocity across it), and for assuming that there is no contribution to the reconnection electric field from latitudinal motion of the merging line.

The DMSP spacecraft can also supply snapshot pictures of ionospheric convection during the interval, allowing us to compare the flow characteristics in both hemispheres and hence infer interhemispheric differences in the reconnection scenarios.

Figure 4a presents observations of the horizontal crosstrack velocity measured by the ion-drift meter on DMSP-F13 during a Northern Hemisphere pass at 13:30 UT (black line) and a Southern Hemisphere pass at 14:20 UT (red line) which represent the interval when the IMF clock angle was closest to zero.

Figures $4 \mathrm{c}$ and d illustrate that both passes were closely aligned to the dawn-dusk meridian but offset slightly to the dayside so that they crossed the noon-midnight meridian at 84-86 AACGM latitude. Both the Northern and Southern Hemisphere passes are characterised by a region of sunward flow (positive velocity) around noon. The edges of the sunward flow regions are delineated by the vertical dashed lines. Outside these regions are areas of tailward flow (negative velocity). This flow pattern describes the expected reverse convection cells that are driven by lobe reconnection (see Huang et al. (2000b) and later sections in this paper).

It is also clear in Fig. 4a that the flow measured in the Northern Hemisphere (black) was patchy and/or intermittent, matching the type of flow expected in the winter hemisphere (Knipp et al., 1991; Freeman et al., 1993). By contrast, the flow variations in the Southern Hemisphere (red) were relatively ordered, as is typical of the summer hemisphere convection.

Figure $4 \mathrm{~b}$ presents the variations in potential measured for the two DMSP passes. The dashed lines demarcate the potentials at the edges of the sunward flow regions. As shown in Huang et al. (2000b) and in later sections of this paper, these passes intercept close to the centre of the reverse convection cells. Consequently, the potential difference between these

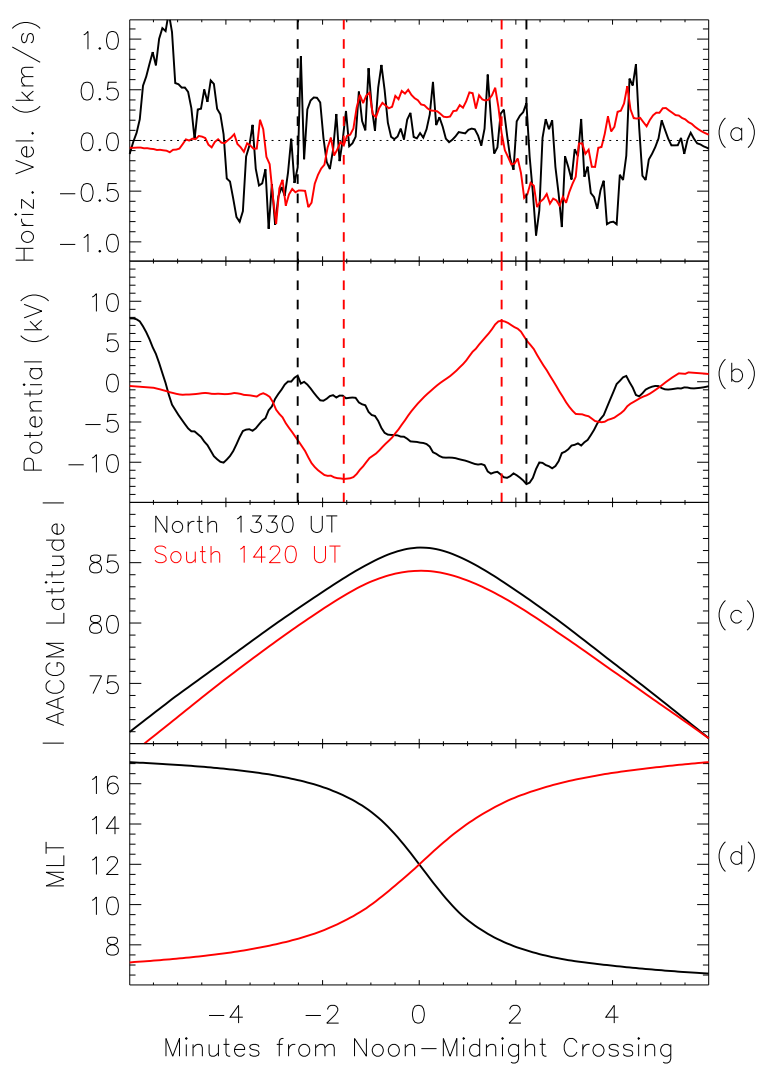

Fig. 4. Data from consecutive DMSP-F13 overpasses of the Northern Hemisphere polar ionosphere (black lines) centred at 13:30 UT, and the Southern Hemisphere polar ionosphere (red lines) centred at 14:20 UT: (a) the horizontal cross-track ion drift volocity, (b) the potential variation, (c) the AACGM latitude of the spacecraft, and (d) the MLT of the spacecraft. The vertical black and red dashed lines delineate the extent of the sunward flow regions and define the approximate centres of the reverse convection cells.

dashed lines represents that associated with lobe reconnection. The potential differences measured were $13.5 \mathrm{kV}$ for the Northern Hemisphere pass and $19.7 \mathrm{kV}$ for the Southern Hemisphere pass.

This hemispheric difference may suggest that magnetic field lines were generally not connected simultaneously in both hemispheres. The potential measured in each hemisphere is the sum of two terms: 1) the potential due to flux closure, which is the same for both hemispheres, and 2) the potential associated with lobe stirring within the polar cap. Hence, the smaller of the potential values measured in the two hemispheres provides an upper limit on the rate of flux closure.

In our observations the smaller potential is $13.5 \mathrm{kV}$, equivalent to a change in polar cap area of $\sim 2.7 \times 10^{8} \mathrm{~m}^{2} / \mathrm{s}$ (assuming an ionospheric magnetic field strength of $5 \times 10^{4} \mathrm{nT}$ ). We can use this value to provide an estimate of the possible poleward velocity of the polar cap boundary of $\sim 40 \mathrm{~m} / \mathrm{s}$, assuming that the radial contraction velocity around the polar cap is uniform and further assuming a circular polar cap of angular radius $10^{\circ}$ (see Fig. 3). 
However, if the contraction velocity is non-uniform around the polar cap, then this poleward velocity estimate would be larger in places.

However, we would still argue that this motion is small in relation to the typical convection velocities observed and hence, supports our previous argument for assuming a quasistationary polar cap scenario. It was possible to measure similar potential values for 7 of the DMSP-F13 overpasses and the results are presented as square symbols in Figs. $2 \mathrm{f}$ and $\mathrm{g}$. The potential values measured are all between 10 and $20 \mathrm{kV}$, with the Southern Hemisphere values being, on average, larger than the Northern Hemisphere values.

\section{Reconnection analysis}

We shall concentrate on measuring reconnection during the sub-interval A (14:40 to 15:20 UT), delineated by the dashed vertical lines in Fig. 2. During interval A the IMF was relatively steady at $B \sim(-3,-1,5) \mathrm{nT}$ with a clock angle $\sim-10^{\circ}$. Because of the steady nature of the IMF at this time, any uncertainty in our estimation of the solar wind propagation time delay is of little importance. The solar wind dynamic pressure was also very steady during interval $\mathrm{A}$ (at $\sim 1 \mathrm{nPa}$ ) and so we would not expect the pressure variations to have a major influence on our ionospheric observations. It was during interval A that the SuperDARN convection mapping provided the most complete ionospheric convection measurements (Sect. 3.3). There was also an observation by the DMSP satellite of a clear reverse cusp ion dispersion which provided the best identifier of the location of the ionospheric projection of the merging line (Sect. 3.2).

\subsection{Technique for estimating the reconnection electric field and potential}

In steady state, and assuming ideal magnetohydrodynamics, the reconnection electric field (or reconnection rate) equates to the component of the ionospheric convection electric field that is directed tangential to the ionospheric projection of the reconnection separatrix (or merging line), in the frame of the separatrix (Vasyliunas, 1984). We can therefore express the reconnection electric field, at a point $i$ and time $t$, by,

$E_{\mathrm{rec}_{\mathrm{i}}}(t)=B_{z_{i}}\left(V_{i}(t) \cos \theta_{i}(t)-V_{P_{i}}(t)\right)$

where $B_{z_{i}}$ represents the vertical magnetic field (AACGM model values assumed), $V_{i}$ represents the convection flow velocity magnitude, $\theta_{i}$ represents the angle between the convection flow velocity vector and the normal to the reconnection separatrix, and $V_{P_{i}}$ represents the velocity of the separatrix $\left(P_{i}\right)$ in the direction of the local normal to the separatrix. Equation (1) allows us to make single point measurements of the reconnection electric field. Assuming that there exist $N$ discrete velocity measurements along the ionospheric pro- jection of the merging line, the total reconnection potential difference can be estimated using

$\phi_{\mathrm{rec}}(t)=\sum_{i=1}^{N} E_{\mathrm{rec}_{\mathrm{i}}}(t) \Delta s_{i}(t)$,

where $\Delta s_{i}$ represents the length of the separatrix portion at measurement location $i$ from the midpoint between the measurements at $i-1$ and $i$ to the midpoint between $i$ and $i+1$. Hence, an estimate of the reconnection electric field and potential requires spatiotemporal measurements of the location of the ionospheric projection of the merging line and of the ionospheric convection velocity local to the merging line.

\subsection{Location of the ionospheric projection of the merging line}

In order to estimate the location of the ionospheric projection of the merging line we use a combination of spectral width measurements from the Goose Bay SuperDARN radar and particle precipitation observations from the DMSP spacecraft. In Fig. 5 we present DMSP-F14 observations of electron and ion precipitation observed over a 5-min interval $(15: 19-15: 24$ UT) that is at the end of interval A. At this time, the DMSP-F14 orbit passed through the noon-sector (see Fig. 3). Starting at 15:20:35 ( 81.5 AACGM latitude), the ion precipitation illustrates a reverse cusp ion dispersion signature (although identified mostly as LLBL precipitation by the Newell et al. (1991) algorithm), where the energy of the precipitating magnetosheath-like ions decreases with decreasing invariant latitude (Burch et al., 1980; Woch and Lundin, 1992; Matsuoka et al., 1996). The poleward edge of this ion dispersion represents a good proxy for the ionospheric projection of the merging line, as it marks the arrival in the ionosphere of the first magnetosheath-like ions from the reconnection site following an interval of reconnection. However, there exists a small (typically $<0.5^{\circ}$ ) latitudinal offset of this proxy from the "true" projection of the merging line, as the footprint will have convected sunward during the finite travel time of the fastest ions from the reconnection site to the ionosphere (Rodger, 2000; Chisham et al., 2002b). We assume that this offset is negligible when compared to other uncertainties in our determination of the location and motion of the merging line and discuss the effect of these uncertainties later in the paper. This DMSP observation provides a single snapshot in time and space of the location of the merging line.

In order to expand on this observation to identify the full spatial extent of the merging line throughout interval A, we need to study other data sets and also make assumptions about the form and stationarity of the merging line. Figure 6 presents the temporal variation of the latitudinal extent of a band of backscatter observed by the meridional pointing beam (beam 4) of the Goose Bay SuperDARN radar, and Doppler spectral width within the band. The Goose Bay observations during this interval are dominated by a band of moderate to high spectral width backscatter $(>\sim 150 \mathrm{~m} / \mathrm{s})$ 
F14

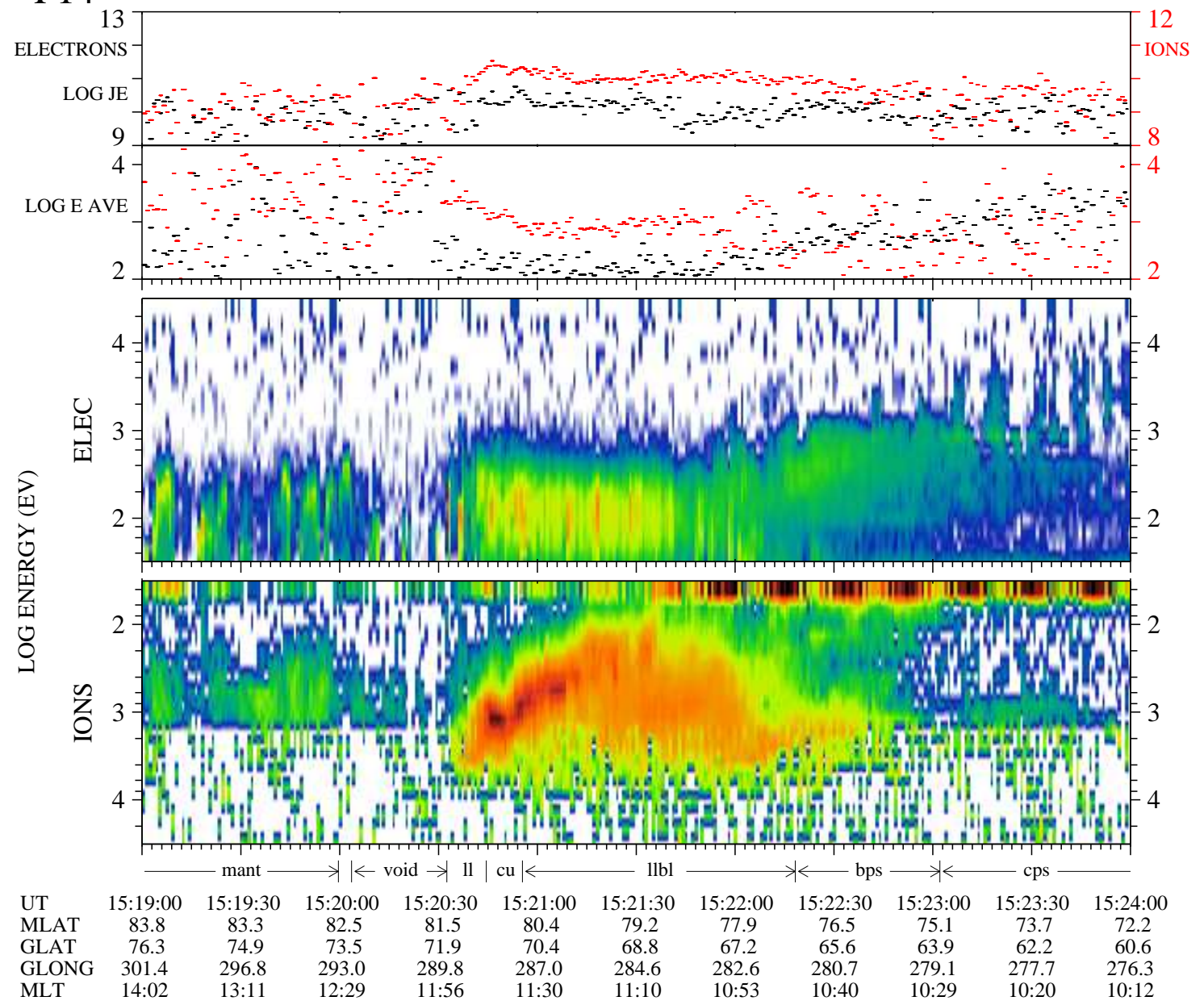

$98 / 315$

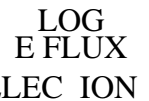

ELEC ION

10 T 8

$5 \perp 3$

Nov 11

JHU/APL

Fig. 5. DMSP-F14 measurements of ion and electron precipitation during the interval 15:19-15:24 UT on 11 November 1998 . The panels, from top to bottom, show integral energy flux in units of $\mathrm{eV} / \mathrm{cm}^{2} \mathrm{~s} \mathrm{sr}$, average energy in $\mathrm{eV}$, and the differential energy flux of electrons and ions in $\mathrm{eV} / \mathrm{cm}^{2} \mathrm{~s} \mathrm{sr} \mathrm{eV}$. Also shown are the classifications of precipitation regions as determined by the algorithm of Newell et al. (1991).

centred around $\sim 80.5^{\circ}$ AACGM latitude. During interval A (marked by the vertical dashed lines in Fig. 6), the backscatter is roughly confined to a restricted latitude range (approximately delineated by the bold horizontal lines in Fig. 6), and varies little.

During southward IMF conditions the equatorward edge of the region of high Doppler spectral width backscatter in the cusp correlates well with the equatorward edge of cusp particle precipitation and so is often used as a proxy for the ionospheric projection of the merging line (which equates to the polar cap boundary under those conditions) (Baker et al., 1995; Chisham and Freeman, 2003). On many occasions, the equatorward edge of the high spectral width region also marks the equatorward edge of the observed backscatter. In these cases, the equatorward backscatter boundary correlates well with the polar cap boundary (Yeoman et al., 1997). No clear correlation has been made during northward IMF conditions between the poleward edge of the cusp particle precipitation (marking the arrival of the first magnetosheath-like ions) and the spectral width and backscatter variations ob- served by the SuperDARN radars. Overplotted on Fig. 6 as a thick dashed black line is the ionospheric footprint of DMSP F14 during the interval presented in Fig. 5 ( 15:1915:23 UT), which passed close to beam 4 of the Goose Bay radar. The thick solid black line plotted over the spacecraft track illustrates the interval where the reverse cusplike ion precipitation was observed by the spacecraft between 15:20:35 and 15:22:20 UT. The poleward edge of this thick line represents the poleward edge of the reverse cusp ion dispersion, and this correlates well with the poleward edge of the backscatter observed by the Goose Bay radar (to within $0.5^{\circ}$ ). This observation, combined with our experience of spectral width variations under southward IMF conditions, suggests that the poleward edge of the backscatter may represent a proxy for the ionospheric footprint of the merging line during northward IMF conditions.

The observational information about the location of the ionospheric projection of the merging line and about the stability of the auroral precipitation regions during the interval of study can be summarised as follows: 


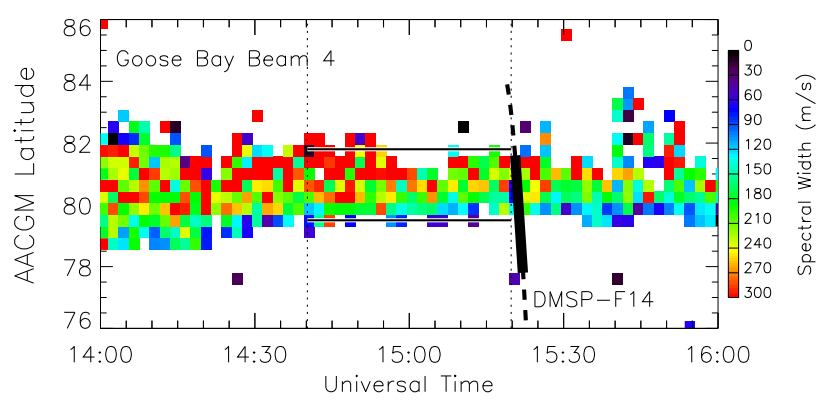

Fig. 6. The variation of spectral width with AACGM latitude and universal time as observed by beam 4 of the Goose Bay SuperDARN radar during the interval 14:00-16:00 UT on 11 November 1998. The vertical dotted lines delineate the sub-interval of data studied in detail in this paper. The horizontal lines delineate the average latitudinal range of the backscatter during this interval. The dashed black line marks the track of the DMSP-F14 spacecraft. The thick black line marks the region of significant ion precipitation (cusp and LLBL) as shown in Fig. 5.

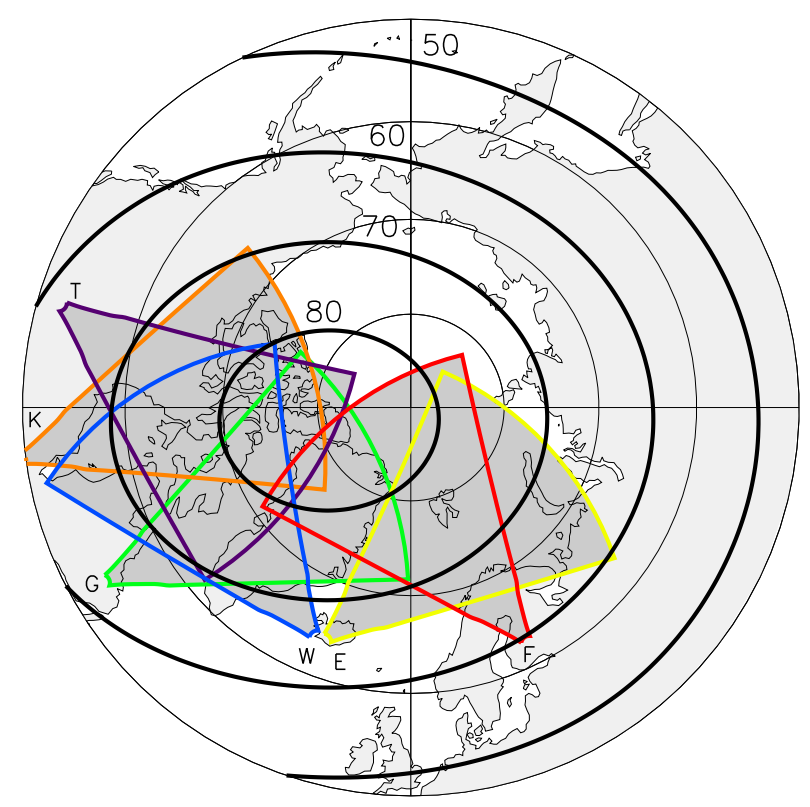

Fig. 7. Map illustrating the fields-of-view of six of the Northern Hemisphere SuperDARN radars (CUTLASS Finland (F), CUTLASS Iceland (E), Iceland West (W), Goose Bay (G), Kapuskasing $(\mathrm{K})$, and Saskatoon $(\mathrm{T})$ ). The bold lines represent lines of constant AACGM latitude (values as shown).

1. The poleward edge of the DMSP reverse cusp ion dispersion provides a single point estimate of the merging line location at $\sim 81.5^{\circ}$ AACGM latitude (Fig. 5).

2. The location of the DMSP merging line estimation matches closely to the poleward edge of the high spectral width backscatter observed by the Goose Bay SuperDARN radar (Fig. 6).

3. The high spectral width backscatter observed by the Goose Bay SuperDARN radar shows little variation in location across interval A; the poleward edge varies between $\sim 81.3^{\circ}$ and $\sim 82.1^{\circ}$ AACGM latitude (Fig. 6 ).

4. The precipitation regions observed by the DMSP spacecraft in the 12-h interval of northward IMF show little variation $\left(< \pm 1^{\circ}\right)$ in location (Fig. 3).

5. The maximum poleward velocity of the merging line that might exist due to the closure of flux is $\sim 40 \mathrm{~m} / \mathrm{s}$.

To use these limited observations to estimate the full spatiotemporal variation of the footprint of the merging line we also need to make the following assumptions about its location and motion:

1. The longitudinal extent of the merging line stretches between the longitudes that mark the centres of the reverse convection cells as determined by the SuperDARN global convection mapping (see next subsection).

2. The merging line is aligned along a line of constant geomagnetic latitude such that $\theta_{i}$ in Eq. (1) represents the angle between the convection velocity and the poleward direction.

3. Any latitudinal motion of the merging line $(<40 \mathrm{~m} / \mathrm{s})$ is small compared to the typical plasma flow across it $(\sim 500 \mathrm{~m} / \mathrm{s})$, and hence, we neglect the $V_{P_{i}}$ term in Eq. (1).

4. The merging line is located at $\sim 81.7^{\circ}$ AACGM latitude, which relates to the average location of the poleward edge of the Goose Bay beam 4 backscatter across interval A.

We discuss the uncertainties introduced by these assumptions later in the paper.

\subsection{Ionospheric convection}

In this section we use the SuperDARN global convection mapping technique (Ruohoniemi and Baker, 1998) to determine the convection velocity field in the Northern Hemisphere ionosphere. We make use of common-mode (2-min sampling) data from six SuperDARN radars in the Northern Hemisphere (CUTLASS Finland (F), CUTLASS Iceland (E), Stokkseyri (W), Goose Bay (G), Kapuskasing (K), and Saskatoon (T)), the fields-of-view of which are presented in Fig. 7. The bold curves in Fig. 7 show the locations of the AACGM latitude contours. SuperDARN global convection maps are produced by fitting line-of-sight velocity information measured by the SuperDARN radars to an expansion of an electrostatic potential function expressed in terms of spherical harmonics. The technique produces a complete equipotential pattern of the convection electric field in the polar ionosphere. In this study we employ a 12 th order spherical harmonic fit and determine the so-called "true" velocity vector variation across the polar ionosphere. 


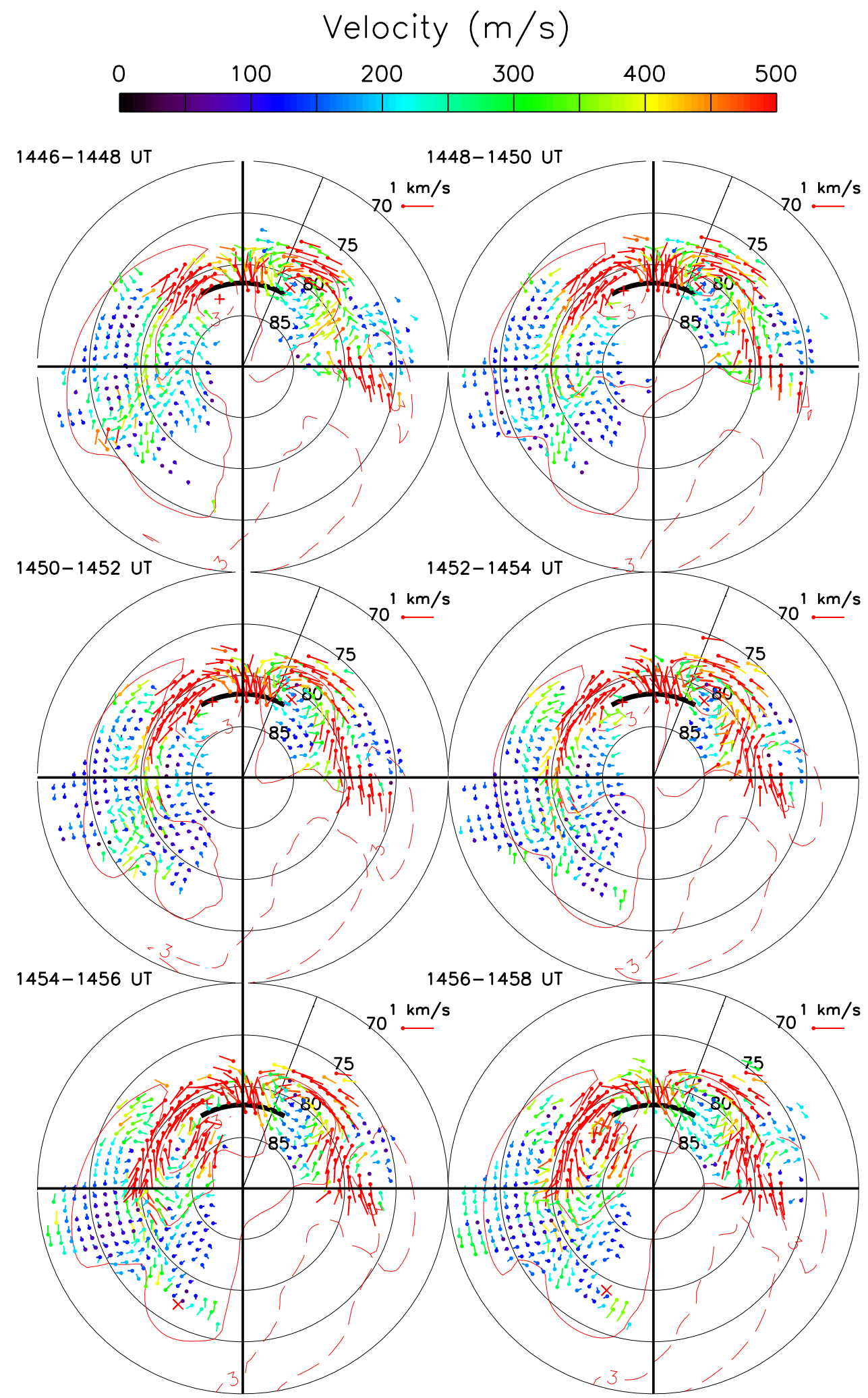

Fig. 8. Six 2-minute global convection maps in the Northern Hemisphere ionosphere covering the interval 14:46-14:58 UT on 11 November 1998. Local magnetic noon (midnight) is at the top (bottom) of each panel and dawn (dusk) is to the right (left). Each map shows the "true" vectors determined by the SuperDARN global convection mapping, colour-coded by their magnitude. The red curves represent equipotentials of the convection electric field with the red crosses denoting the centres of the reverse convection cells. The bold black arc represents the latitude of our estimate of the ionospheric projection of the merging line. 


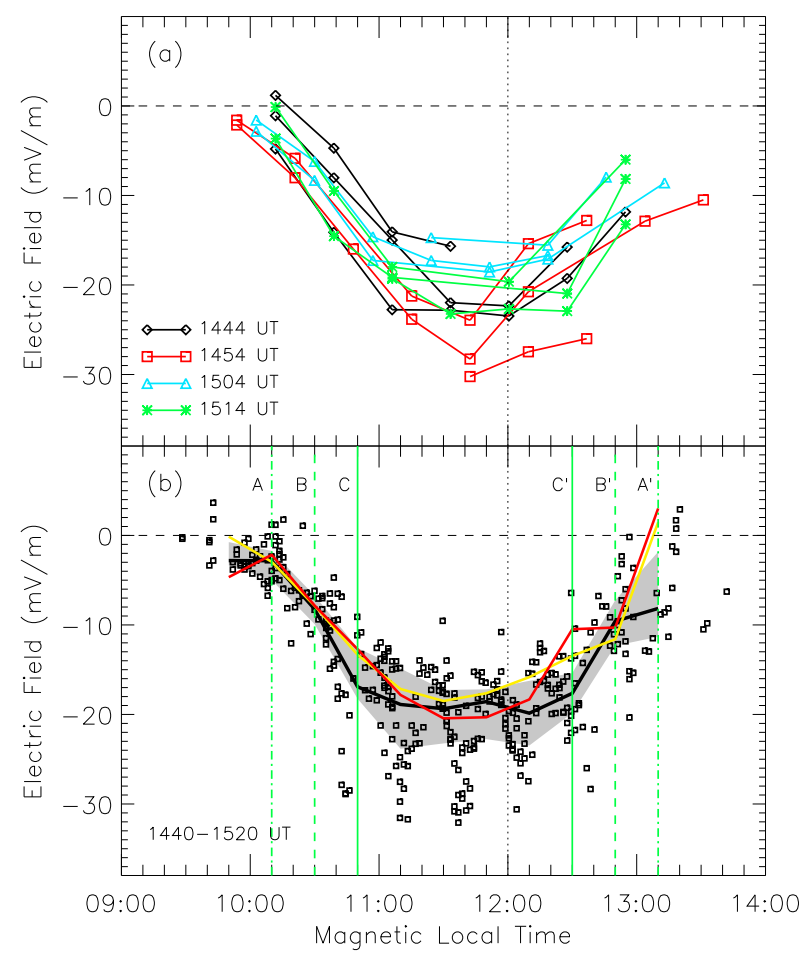

Fig. 9. The spatial variation (with MLT) of the reconnection electric field along the ionospheric projection of the X-line. (a) The spatial variation of the reconnection electric field for four selected 2-min intervals (times as shown). (b) All the reconnection electric field values measured in the interval 14:40-15:20 UT (square symbols) using the velocity vectors at $81.5^{\circ}$ latitude. The bold black line represents the variation of the median electric field value when the estimates are organised into 20-min bins. The grey-shaded region represents the upper and lower quartiles of this electric field distribution. The bold yellow line represents the median of the electric field values that result when using the vectors located at $80.5^{\circ}$ latitude. The bold red line represents the median of the electric field values that result when using the vectors located at $82.5^{\circ}$ latitude. The vertical solid, dashed, and dot-dashed green lines mark the approximate extent of the X-line when assuming that it is best described by the extent of the maximum electric field, the half-width of the electric field distribution and the minimum electric field, respectively.

This provides the best estimate of mesoscale flow variations (Chisham et al., 2002a). Before the fitting, the SuperDARN line-of-sight velocity data have been preprocessed using the methods of Chisham and Pinnock (2002) to remove all non$F$-region backscatter. The ionospheric convection during this interval, as measured by the SuperDARN radar network, was first studied by Huang et al. (2000b), although not using the same data processing that we employ here.

Figure 8 presents six consecutive 2-min snapshots of the convection velocity field (from 14:46-14:58 UT). In each map, magnetic local noon (midnight) is located at the top (bottom) of the map and dawn (dusk) is to the right (left). Each convection map presents the "true" velocity vectors determined for each 2-min interval, colour-coded by velocity magnitude. The maps also present the equipotential contours of the convection electric field determined from the mapping (thin red solid and dashed lines). The full equipotential pattern is determined from a combination of the measured radar velocity data complemented by model velocity data (Ruohoniemi and Greenwald, 1996) in the regions where no radar data exist. However, we only derive reconnection rates in regions where measured (non-model) velocity data have been used to determine the velocity vectors. The thick black curve on each map highlights the estimated latitude of the ionospheric footprint of the merging line as discussed in the previous section.

There are a number of common features in all the convection maps:

1. There are strong equatorward (sunward) flows $(\sim 500$ $800 \mathrm{~m} / \mathrm{s}$ ) which cross the merging line around the noon sector.

2. There are two small reverse convection cells in the dayside ionosphere. The estimated merging line extends approximately between the centres of these two convection cells.

3. The flow in the dawn and dusk sectors shows low velocities at high and low latitudes and a narrow band of high antisunward flow at around $\sim 80^{\circ}$ AACGM latitude.

There exist nearly a complete set of vectors at $81.5^{\circ}$ AACGM latitude in the dayside ionosphere, which represent the closest set of vectors to the estimated location of the merging line (mapped vectors are located at $1^{\circ}$ latitude intervals). We use these velocity vectors as our best estimate of the convection velocity variation at the merging line. To investigate the effects of uncertainties in the velocity field and the location of the merging line we also repeat the analysis with the vectors that are located at $80.5^{\circ}$ and $82.5^{\circ}$.

\subsection{Spatial variation of the reconnection electric field}

Using Eq. (1), the spatial variation of the reconnection electric field along the merging line was determined for each 2min interval during the period 14:40-15:20 UT (interval A). Figure 9a presents these spatial variations (with magnetic local time (MLT)) for 4 of the 2-min intervals (those commencing at 14:44 (black lines), 14:54 (red), 15:04 (blue), and 15:14 (green) UT). For each time interval there is typically more than one estimate of the electric field at each MLT. This is because a "true" velocity vector estimate exists for each SuperDARN radar that provided line-of-sight velocity data to the region in question (Chisham et al., 2002a). Although this results in an ambiguity in the electric field values, the extent of their variation at any time and location provides information about the uncertainty of the electric field estimates. The electric field variations in Fig. 9a show that, although they vary somewhat in magnitude with time, the shape and extent of the electric field variation in MLT is preserved throughout the whole interval. 


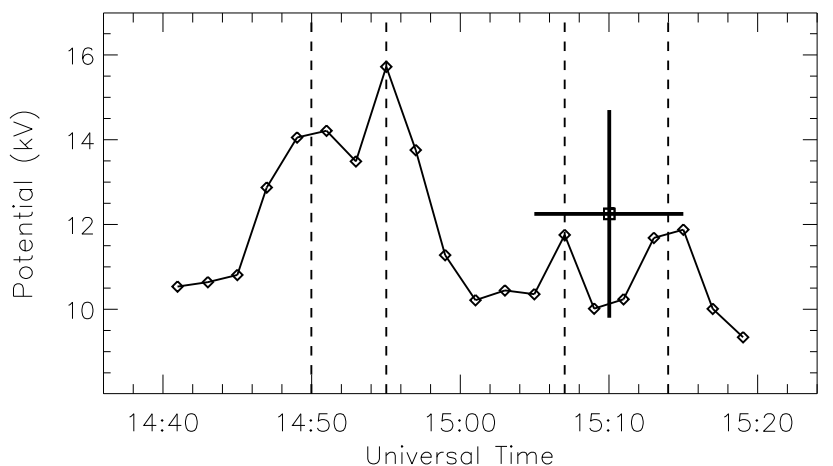

Fig. 10. The temporal variation of the reconnection potential (solid line and diamonds). The square with the bold error bars represents the potential measured between the centres of the reverse convection cells during a DMSP-F13 overpass. The vertical dashed lines highlight transient enhancements in the reconnection potential.

In Fig. 9b we present, as square symbols, all the reconnection electric field values measured during interval A. Although the spread of the electric field values is quite large (ranging from $\sim 14$ to $\sim 33 \mathrm{mV} / \mathrm{m}$ at the peak location), mainly due to the temporal variation of the reconnection electric field, the shape of the electric field variation with MLT is preserved. The bold black line and the grey-shaded region illustrate the median and quartile range of the electric field distribution, respectively, resulting from organising the data into 20-min MLT bins. This highlights the typical shape of the spatial variation of the reconnection electric field. Figure $9 \mathrm{~b}$ shows that the width of the ionospheric projection of the X-line is at least $1.67 \mathrm{~h}$ of MLT where the reconnection electric field is a maximum (delineated by the vertical solid lines $\mathrm{C}$ and $\mathrm{C}^{\prime}$ ) and probably $\sim 3.0 \mathrm{~h}$ of MLT where the reconnection electric field approaches zero (A-A'). In the former case $\mathrm{C}-\mathrm{C}$ ', the finite reconnection electric field values outside this region would be explained as a result of smoothing of the velocity field during the SuperDARN convection mapping process.

\subsection{Temporal variation of the reconnection potential}

The reconnection electric field estimates measured during each 2-min interval were summed along the length of the $\mathrm{X}$-line using Eq. (2), to provide an estimate of the temporal variation of the total reconnection potential. In this calculation we assumed A-A' to represent the length of the Xline and took the average electric field in cases where more than one electric field estimate existed at a single MLT. We present this variation in Fig. 10. These potential values represent those that exist between the centres of the two reverse convection cells, and hence, assuming that any field-aligned potential drop is close to zero along the merging line, they also describe the reconnection potential variation along the in-situ X-line on the lobe magnetopause. The square symbol with bold error bars in Fig. 10 represents the measurement of the potential made by DMSP-F13 during this interval, which
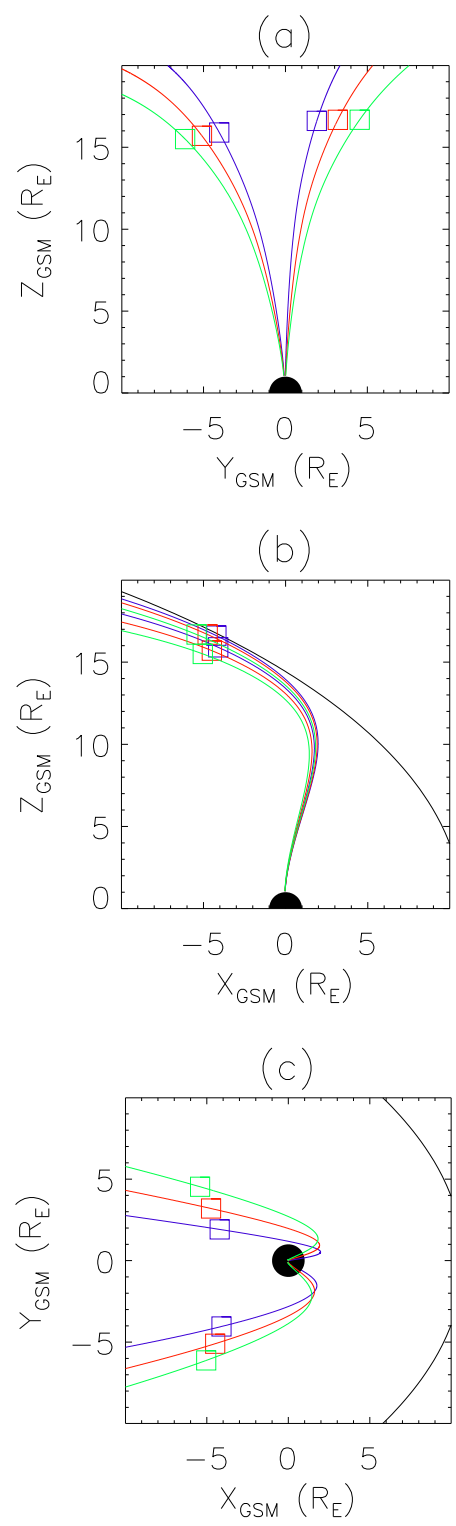

Fig. 11. The paths of magnetic field lines mapped from the ends of the estimated merging line location in the ionosphere to the lobe magnetopause, using the Tsyganenko 96 magnetospheric magnetic field model. Panels (a), (b), and (c) represent the projections into the $y-z, x-z$, and $x-y$ GSM planes, respectively. The three coloured field lines represent mappings for the three assumptions regarding the X-line length (see text for details). The square symbols represent the best estimates of the ends of the in-situ X-line (see text for details).

compares well with our observations. The potential values we observe are low $(\sim 10-16 \mathrm{kV})$ but are consistent with the lower range of the values typically observed under these conditions ( $\sim 10-30 \mathrm{kV})$ (Weimer, 1995). It must also be remembered that the reconnection potential is generally observed to be lower in the winter hemisphere where these observations have been made (Freeman et al., 1993; Cumnock et al., 1995). 
Although we only present $40 \mathrm{~min}$ of data, Fig. 10 illustrates that there is a lot of temporal variability in the reconnection potential. The dashed vertical lines illustrate the times of the peak reconnection potential during transient enhancements of the potential. These lines highlight transient features that last $\sim 4-15 \mathrm{~min}$ and that recur on a similar time scale. This is not to say that transient features do not occur on other time scales but our observations are restricted by our sampling size $(2 \mathrm{~min})$, our interval size $(40 \mathrm{~min})$, and by the median filtering of data within the convection mapping process.

\subsection{Mapping to the magnetopause}

By mapping our results to the lobe magnetopause we can estimate the extent of the reconnection region and the reconnection electric field values that we would expect to see there. We assume that magnetic field lines are equipotentials (i.e. steady state, ideal MHD), and take the two end points of our ionospheric X-line and trace the magnetic field lines from these two points to the magnetopause. We use the Tsyganenko 96 magnetospheric field model (Tsyganenko, 1995; Tsyganenko and Stern, 1996) to perform the field line tracing. This model has an explicitly-prescribed ellipsoidal magnetopause and, in principle, the point on a field line at which reconnection is expected to take place is the point where the field line just touches the model magnetopause. The magnetopause reconnection X-line can be described as an arc on the magnetopause surface that connects the mapped locations of the two end points of the ionospheric projection of the Xline. In calculating the extent of the magnetopause X-line, we approximate this arc on the ellipsoidal magnetopause by an arc on the circle formed by the cross section through the magnetopause in the $y-z$ plane, the $x$-coordinate of which is the average of the $x$-coordinates of the two points.

In practice, there is always some finite distance in the numerical model between the field line along which we are tracing and the ellipsoidal magnetopause. We therefore need some method for estimating the most likely location of the reconnection site on the field line. Our method uses the scaling characteristic of the Tsyganenko 96 model. This model utilises an ellipsoidal coordinate system $(\sigma, \tau, \phi)$; the $\sigma$ coordinate surface is a set of nested ellipsoids, and the model magnetopause is chosen to be one of these ellipsoidal surfaces, the size of the magnetopause scaling self-similarly with solar wind dynamic pressure. We choose to place the model reconnection site at the location on the field line at which the $\sigma$ coordinate reaches its maximum value. This is the point at which the magnetopause would first encounter the field line, if the magnetopause were shrunk self-similarly while holding the rest of the model constant.

Section 3.4 gives three different estimates of the ionospheric X-line width, based on (a) the region A-A' where the electric field magnitude is greater than zero, (b) the region B-B' between the half-height points of the median electric field, and (c) the region $\mathrm{C}-\mathrm{C}^{\prime}$ where the electric field is a maximum. We perform the field line mapping for each of these three cases, enabling us to estimate a range of mag- netopause X-line widths. The results of the field line mapping are shown in Fig. 11. Figures 11a, b, and c present the field line mapping projected into the $y-z, x-z$, and $x-y$ GSM planes, respectively. The green lines represent the mapping for case (a) described above, the red for case (b), and the blue for case (c). The square symbols represent the estimated locations of the end points of the magnetopause X-line (where the field lines meet the model magnetopause). The $\mathrm{X}$-line length varies depending on the assumptions made, being $11.2 \pm 1.2 \mathrm{R}_{E}$ for case (a), $8.7 \pm 0.8 \mathrm{R}_{E}$ for case (b), and $6.2 \pm 0.6 \mathrm{R}_{E}$ for case (c). When the potential values are mapped to the magnetopause reconnection $\mathrm{X}$-line, the average electric field across the peak region (between the blue lines) is $\sim 0.2 \mathrm{mV} / \mathrm{m}$.

\section{Discussion}

In our introduction, we presented two possible ionospheric convection scenarios that exist during northward IMF conditions: merging cells where flux closure occurs, and lobe cells where no flux closure occurs. The ionospheric convection during this interval was first studied by Huang et al. (2000b). They showed that four-cell convection patterns existed in the Northern Hemisphere for much of the interval and that the DMSP observations in the Southern Hemisphere were also consistent with a four-cell structure. They suggested that this implied that the reverse convection cells were merging cells and not lobe cells and hence, that new closed flux was being created. In our analysis, we noted the typically different potentials in the two hemispheres. However, Fig. 3 suggests that the polar cap is approximately static throughout the whole northward IMF interval. Hence, our results suggest that merging may have been occurring in both hemispheres simultaneously but it is likely that much of this would have been occurring on different magnetosheath field lines such that there is both flux closure and lobe cell stirring.

Our observations have presented a clear picture, for the first time, of the spatial variation of the reconnection rate during northward IMF conditions. This spatial variation is characterized by its uniformity along the centre of the Xline, although it is unclear whether the variation at the ends of the X-line is real or is a result of smoothing in the analysis process. It is interesting to compare these measurements with those made by Pinnock et al. (2003) during southward IMF conditions. The X-line of Pinnock et al. (2003) mapped to a region of the low-latitude magnetopause of $\sim 38 \mathrm{R}_{E}$ in extent, much larger than the $\sim 6-11 \mathrm{R}_{E}$ estimated for our study. This is as predicted by the anti-parallel merging hypothesis in which only a small region of the high-latitude magnetopause satisfies the anti-parallel criterion when the IMF is northward. Our mapped reconnection X-line matches well with the predicted anti-parallel regions on the magnetopause for these conditions. The magnetic shear between the lobe field lines and perfectly-draped magnetosheath field lines along the projected magnetopause $\mathrm{X}$-line is $<20^{\circ}$ for the whole of the X-line. During the event of Pinnock et al. 
(2003) the reconnection rate along the ionospheric projection of the X-line appeared more spatially variable, ranging from $\sim 5 \mathrm{mV} / \mathrm{m}$ to $\sim 40 \mathrm{mV} / \mathrm{m}$ at different locations along the $\mathrm{X}$ line. Although observing similar spatially-averaged reconnection rates in the ionosphere, the magnetopause reconnection rate implied by the observations of Pinnock et al. (2003) was $\sim 0.5 \mathrm{mV} / \mathrm{m}$, more than double that implied by our observations.

Phan et al. (2003) mapped auroral emissions associated with high-latitude reconnection during northward IMF conditions to the lobe magnetopause and implied an X-line of at least $3.6 \mathrm{R}_{E}$ in the GSM y-direction. This is much smaller than our estimates of an X-line length of $\sim 6-11 \mathrm{R}_{E}$. This may be because the auroral emissions observed by Phan et al. (2003) do not extend along the whole of the ionospheric projection of the X-line. Auroral emissions are generally observed in upward field-aligned current regions. The fieldaligned currents consistent with the reverse convection cell pattern are downward in the post-noon region and upward in the pre-noon region, and hence, it is reasonable to think that auroral emissions would cover about half of the longitudinal extent of the merging line. In this case, the observations of Phan et al. (2003) are consistent with our estimate of the extent of the merging line.

It is difficult to meaningfully estimate the physical uncertainties in our estimate of the location (and extent) of the in-situ X-line. However, it is easy to quantify the numerical uncertainty in the field line mapping due to the finite resolution of the model. Our range of possible X-line locations is the segment of the field line over which the $\sigma$ coordinate is equal to its maximum value. In all cases, this range is less than $0.5 \mathrm{R}_{E}$. If our assumption concerning the placement of the $\mathrm{X}$-line is in error, then it is interesting to consider how much our X-line length and reconnection electric field values would change by considering the $\mathrm{X}$-line to be located at other points on the field line. One such point is the field line kink in the exterior cusp, where the field line first starts to turn tailward. At this point the X-line lengths would be approximately half of those estimated above (being $\sim 3-6 \mathrm{R}_{E}$ ), matching closer to the length implied by the analysis of Phan et al. (2003). Consequently, the reconnection electric field in this case would be doubled (to $\sim 0.4 \mathrm{mV} / \mathrm{m}$ ), matching closer the values measured by Pinnock et al. (2003) during southward IMF conditions.

Our measurements of the temporal variation of the reconnection potential suggests that reconnection is temporally variable during northward IMF conditions. However, there is a background potential level of $\sim 10 \mathrm{kV}$ which might suggest that reconnection is continually ongoing, but enhanced in bursts. There has been a lot of debate as to whether reconnection is typically pulsed or steady, with much evidence that illustrates that reconnection is pulsed during southward IMF conditions (Lockwood and Smith, 1992). During northward IMF conditions, when reconnection is predicted to occur on the lobe magnetopause tailward of the cusp, gas dynamic models predict that the local magnetosheath flow will be super-Alfvénic. It has been predicted that reconnection in such regions of super-Alfvénic magnetosheath flow will always be transient in nature (Rodger et al., 2000). However, Phan et al. (2003) have recently measured sub-Alfvénic magnetosheath flows in this region, suggesting that steady lobe reconnection can occur under northward IMF conditions. Our observations of a temporally variable reconnection rate superimposed on a background level of reconnection, are consistent with both of these hypotheses. The temporal nature of the reconnection potential is further highlighted by the observation of cusp ion steps in the reverse cusp ion dispersion (see Fig. 5) which are typically thought to be a signature of pulsed reconnection (Morley and Lockwood, 2003).

In order to appreciate the level of quantitative accuracy in the measurements of the reconnection electric field and potential that we have presented above, we need to fully understand the errors and uncertainties in the measured quantities and those introduced by the assumptions made during the analysis process. These uncertainties have a number of sources:

1. The uncertainty arising from a latitudinal misplacement of the merging line. Earlier, we suggested that the latitudinal uncertainty in the placement of the X-line would be less than $1^{\circ}$. To illustrate the effect of such an error we have repeated our analysis for the cases when the ionospheric projection of the X-line is located at $80.5^{\circ}$ latitude, and when it is located at $82.5^{\circ}$ latitude. In Fig. 9b we present the spatial variation of the median reconnection electric field values for the measurements made at $80.5^{\circ}$ (bold yellow line) and $82.5^{\circ}$ (bold red line) for comparison with that made at $81.5^{\circ}$ (bold black line). The median electric field variations at $80.5^{\circ}$ and $82.5^{\circ}$ are very similar, if slightly smaller in magnitude, to that determined at $81.5^{\circ}$. This suggests that differences in the total potential values due to this effect would be $<\sim 5 \%$.

2. The uncertainty arising from a possible tilt or kink of the merging line. This will introduce uncertainties in the determination of the flow velocity component across the merging line. If we denote the unknown tilt of the reconnection separatrix with respect to our assumed separatrix as $\alpha$, then the perpendicular flow velocity component across the separatrix in Eq. (1) is actually $V_{i}(t) \cos \left(\theta_{i}(t)+\alpha(t)\right)$. Hence, the magnitude of the effect depends on the size of $\alpha$ with respect to $\theta_{i}$. Our data show little suggestion of a consistent tilt in the merging line, although there are times when the data are suggestive of tilts of up to $\sim 5^{\circ}$. The error in the perpendicular flow component across the boundary, for a tilt of $\sim 5^{\circ}$, will always be $<\sim 0.1 V_{i}$, although this can be a significant effect for vectors for which $\theta_{i} \sim 90^{\circ}$. For our event, $\theta_{i} \sim 0^{\circ}-30^{\circ}$ for the majority of the velocity vectors and hence, the uncertainty is likely to be $<\sim 0.05 V_{i}$.

3. The uncertainty arising from motion of the merging line. Earlier in the paper we determined that the maximum average speed of any boundary motion associated 
with a contraction of the polar cap would be $\sim 40 \mathrm{~m} / \mathrm{s}$. However, it is still possible that there were transient poleward and equatorward jumps in the merging line during this interval that would have introduced more temporal variability in the reconnection electric field and potential. Hence, it may be that the transient features seen in Fig. 10 represent just part of the true temporal variability in the reconnection potential during this time.

4. The uncertainty in the velocity vectors. This includes errors in the range location of line-of-sight velocity values, the velocity error estimated in the raw SuperDARN data processing (FITACF), and changes to the velocity that occur in the convection mapping process, e.g. through spatial and temporal median filtering of the data. Yeoman et al. (2001) showed that the ground range location of backscatter was accurate to within $\sim 60 \mathrm{~km}$ for 1.5-hop backscatter such as that used in this paper. However, this uncertainty is within the $1^{\circ}(\sim 110 \mathrm{~km})$ cell size employed within the convection mapping process. Hence, this is unlikely to have much of an effect on the measured reconnection parameters. As discussed by Ruohoniemi and Baker (1998), characterising the uncertainty in the convection mapping process is very difficult. The major side effect of the mapping process is likely to be a smoothing of the temporal variability in the reconnection electric field and potential. Hence, it is possible that small-scale temporal variability in the reconnection potential has been reduced.

\section{Summary and conclusions}

In this paper we have presented, for the first time, a detailed spatiotemporal picture of high-latitude dayside reconnection during northward IMF conditions. In order to determine the location of the ionospheric projection of the merging line, we have shown, for the first time, that the poleward edge of the reverse cusp ion dispersion (which represents a good proxy for the merging line under northward IMF conditions) matches well with the poleward edge of backscatter (with elevated spectral width) observed by the SuperDARN radars. Combining an estimate of the merging line location with the spatiotemporal variation in the convection velocity field provided by the SuperDARN radars allowed for a detailed study of the reconnection electric field. The measured spatial variation of the reconnection electric field along the X-line was shown to be constant in shape but variable in magnitude, leading to transient enhancements in the measured reconnection potential. Our field line mapping suggested that the values of the X-line extent and the reconnection electric field on the lobe magnetopause were $\sim 6-11 \mathrm{R}_{E}$ and $\sim 0.2 \mathrm{mV} / \mathrm{m}$, respectively.

Acknowledgements. We would like to thank the principal investigators of SuperDARN radars used in this study; R. A. Greenwald
(Goose Bay and Kapuskasing) and J.-P. Villain (Stokkseyri). CUTLASS is supported by the Particle Physics and Astronomy Research Council, UK, the Swedish Institute for Space Physics, Uppsala, and the Finnish Meteorological Institute, Helsinki. Support for the Goose Bay and Kapuskasing radars is provided in part by the NSF and in part by NASA. Support for the Stokkseyri radar is provided by the CNRS/INSU. Support for the Saskatoon radar is provided by NSERC, Canada. The DMSP particle detectors were designed by D. Hardy of AFRL, and data obtained from JHU/APL. We thank D. Hardy, F. Rich, and P. T. Newell for its use. DMSP ion-drift data and analysis were provided under NSF grant ATM-9713436 and NASA grant NAG5-9297. The WIND and ACE data are part of the CDAWeb database. We are grateful to R. Lepping, principal investigator on the WIND MFI instrument, K. Ogilvie, principal investigator on the WIND SWE instrument, and N. F. Ness, principal investigator on the ACE MFI instrument.

Topical Editor T. Pulkkinen thanks two referees for their help in evaluating this paper.

\section{References}

Baker, K. B., Dudeney, J. R., Greenwald, R. A., Pinnock, M., Newell, P. T., Rodger, A. S., Mattin, N., and Meng, C.-I.: HF radar signatures of the cusp and low-latitude boundary layer, J. Geophys. Res., 100, 7671-7695, 1995.

Baker, K. B., Rodger, A. S., and Lu, G.: HF-radar observations of the dayside magnetic merging rate: A Geospace Environment Modeling boundary layer campaign study, J. Geophys. Res., 102, 9603-9617, 1997.

Blanchard, G. T., Ellington, C. L., Lyons, L. R., and Rich, F. J.: Incoherent scatter radar identification of the dayside magnetic separatrix and measurement of magnetic reconnection, J. Geophys. Res., 106, 8185-8195, 2001.

Burch, J. L., Reiff, P. H., Spiro, R. W., Heelis, R. A., and Fields, S. A.: Cusp region particle precipitation and ion convection for northward interplanetary magnetic field, Geophys. Res. Lett., 7, 393-396, 1980.

Burch, J. L., Reiff, P. H., Menietti, J. D., Heelis, R. A., Hanson, W. B., Shawhan, S. D., Shelley, E. G., Sugiura, M., Weimer, D. R., and Winningham, J. D.: IMF $B_{y}$-dependent plasma flow and Birkeland currents in the dayside magnetosphere, 1, Dynamics Explorer observations, J. Geophys. Res., 90, 1577-1593, 1985.

Burke, W. J., Kelley, M. C., Sagalyn, R. C., Smiddy, M., and Lai, S. T.: Polar cap electric field structures with a northward interplanetary magnetic field, Geophys. Res. Lett., 6, 21-24, 1979.

Chisham, G. and Freeman, M. P.: A technique for accurately determining the cusp-region polar cap boundary using SuperDARN HF radar measurements, Ann. Geophys., 21, 983-996, 2003.

Chisham, G. and Pinnock, M.: Assessing the contamination of SuperDARN global convection maps by non- $F$-region backscatter, Ann. Geophys., 20, 13-28, 2002.

Chisham, G., Coleman, I. J., Freeman, M. P., Pinnock, M., and Lester, M.: Ionospheric signatures of split reconnection X-lines during conditions of IMF $B_{z}<0$ and $\left|B_{y}\right| \sim\left|B_{z}\right|$ : Evidence for the antiparallel merging hypothesis, J. Geophys. Res., 107(A10), 1323, doi:10.1029/2001JA009124, 2002a.

Chisham, G., Pinnock, M., Coleman, I. J., Hairston, M. R., and Walker, A. D. M: An unusual geometry of the ionospheric signature of the cusp: Implications for magnetopause merging sites, Ann. Geophys., 20, 29-40, 2002b. 
Crooker, N. U.: Reverse convection, J. Geophys. Res., 97, 1936319372, 1992.

Crooker, N. U. and Rich, F. J.: Lobe cell convection as a summer phenomenon, J. Geophys. Res., 98, 13 403-13 407, 1993.

Cumnock, J. A., Heelis, R. A., Hairston, M. R., and Newell, P. T.: High-latitude ionospheric convection pattern during steady northward interplanetary magnetic field, J. Geophys. Res., 100, 14 537-14 555, 1995.

Dungey, J. W.: The structure of the ionosphere, or adventures in velocity space, in Geophysics: The Earth's Environment, edited by C. DeWitt, J. Hiebolt, and A. Lebeau, 526-536, Gordon and Breach, New York, 1963.

Freeman, M. P., Farrugia, C. J., Burlaga, L. F., Hairston, M. R., Greenspan, M. E., Ruohoniemi, J. M., and Lepping, R. P.: The interaction of a magnetic cloud with the earth: Ionospheric convection in the Northern and Southern Hemispheres for a wide range of quasi-steady interplanetary magnetic field conditions, J. Geophys. Res., 98, 7633-7655, 1993.

Greenwald, R. A., Baker, K. B., Dudeney, J. R., Pinnock, M., Jones, T. B., Thomas, E. C., Villain, J.-P., Cerisier, J.-C., Senior, C., Hanuise, C., Hunsucker, R. D., Sofko, G., Koehler, J., Nielsen, E., Pellinen, R., Walker, A. D. M., Sato, N., and Yamagishi, H.: DARN/SuperDARN: A global view of the dynamics of highlatitude convection, Space Sci. Rev., 71, 761-796, 1995.

Gosling, J. T., Thomsen, M. F., Bame, S. J., Elphic, R. C., and Russell, C. T.: Observations of reconnection of interplanetary and lobe magnetic field lines at the high-latitude magnetopause, J. Geophys. Res., 96, 14 097-14 106, 1991.

Hardy, D. A., Schmitt, L. K., Gussenhoven, M. S., Marshall, F. J., Yeh, H. C., Shumaker, T. L., Hube, A., and Pantazis, J.: Precipitating electron and ion detectors (SSJ/4) for the block 5D/flights 6-10 DMSP satellites: Calibration and data presentation, Rep. AFGL-TR-84-0317, Air Force Geophys. Lab., Hanscam AFB, Mass., 1984.

Heelis, R. A.: The effects of interplanetary magnetic field orientation on dayside high latitude ionospheric convection, J. Geophys. Res., 89, 2873-2880, 1984.

Heelis, R. A., Reiff, P. H., Winningham, J. D., and Hanson, W. B.: Ionospheric convection signatures observed by DE2 during northward interplanetary magnetic field, J. Geophys. Res., 91, 5817-5830, 1986

Huang, C.-S., Andre, D. A., Sofko, G. J., and Kustov, A. V.: Super Dual Auroral Radar Network observations of ionospheric multicell convection during northward interplanetary magnetic field, J. Geophys. Res., 105, 7419-7428, 2000 a.

Huang, C.-S., Sofko, G. J., Koustov, A. V., Andre, D. A., Ruohoniemi, J. M., Greenwald, R. A., and Hairston, M. R.: Evolution of ionospheric multicell convection during northward interplanetary magnetic field with $\left|B_{z} / B_{y}\right|>1$ J. Geophys. Res., 105, 27 095-27 107, 2000b.

Kessel, R. L., Chen, S.-H., Green, J. L., Fung, S. F., Boardsen, S. A., Tan, L. C., Eastman, T. E., Craven, J. D., and Frank, L. A.: Evidence of high-latitude reconnecting during northward IMF: Hawkeye observations, Geophys. Res. Lett., 23, 583-586, 1996.

Knipp, D. J., Richmond, A. D., Emery, B., Crooker, N. U., de la Beaujardiere, O., Evans, D., and Kroehl, H.: Ionospheric convection response to changing IMF direction, Geophys. Res. Lett., 18, 721-724, 1991.

Lockwood, M. and Smith, M. F.: The variation of reconnection rate at the dayside magnetopause and cusp ion precipiation, J. Geophys. Res., 97, 14 841-14 847, 1992.

Lockwood, M. and Moen, J.: Reconfiguration and closure of lobe flux by reconnection during northward IMF: Evidence for signatures in cusp/cleft auroral emissions, Ann. Geophys., 17, 9961011, 1999.

Maezawa, K.: Magnetospheric convection induced by the positive and negative $z$ components of the interplanetary magnetic field: Quantitative analysis using polar cap magnetic records, J. Geophys. Res., 81, 2289-2303, 1976.

Matsuoka, A., Tsuruda, K., Hayakawa, H., Mukai, T., and Nishida, A.: Electric field structure and ion precipitation in the polar region associated with northward interplanetary magnetic field, J. Geophys. Res., 101, 10711-10736, 1996.

Milan, S. E., Lester, M., Cowley, S. W. H., Oksavik, K., Brittnacher, M., Greenwald, R. A., Sofko, G., and Villain, J.-P.: Variations in the polar cap area during two substorm cycles, Ann. Geophys., 21, 1121-1140, 2003.

Morley, S. K. and Lockwood, M.: The dependence of cusp ion signatures on the reconnection rate, Ann. Geophys., 21, 947-953, 2003.

Newell, P. T., Burke, W. J., Sanchez, E. R., Meng, C.-I., Greenspan, M. E., and Clauer, C. R.: The low latitude boundary layer and the boundary plasma sheet at low altitude: prenoon precipitation regions and convection reversal boundaries, J. Geophys. Res., 96, $21013-21023,1991$.

Onsager, T. G. and Lockwood, M.: High-latitude particle precipitation and its relationship to magnetospheric source regions, Space Sci. Rev., 80, 77-107, 1997.

Onsager, T. G., Scudder, J. D., Lockwood, M., and Russell, C. T.: Reconnection at the high-latitude magnetopause during northward interplanetary magnetic field conditions, J. Geophys. Res., 106, 25 467-25 488, 2001.

Phan, T., Frey, H. U., Frey, S., Peticolas, L., Fuselier, S., Carlson, C., Rème, H., Bosqued, J.-M., Balogh, A., Dunlop, M., Kistler, L., Mouikis, C., Dandouras, I., Sauvaud, J.-A., Mende, S., McFadden, J., Parks, G., Moebius, E., Klecker, B., Paschmann, G., Fujimoto, M., Petrinec, S., Marcucci, M. F., Korth, A., and Lundin, R.: Simultaneous Cluster and IMAGE observations of cusp reconnection and auroral proton spot for northward IMF, Geophys. Res. Lett., 30, 1509, doi:10.1029/2003GL016885, 2003.

Pinnock, M., Rodger, A. S., Baker, K. B., Lu, G., and Hairston, M.: Conjugate observations of the day-side reconnection electric field: A GEM boundary layer campaign, Ann. Geophys., 17, 443-454, 1999.

Pinnock, M., Chisham, G., Coleman, I. J., Freeman, M. P., Hairston, M., and Villain, J.-P.: The location and rate of dayside reconnection during an interval of southward interplanetary magnetic field, Ann. Geophys., 21, 1467-1482, 2003.

Reiff, P. H. and Burch, J. L.: IMF $B_{y}$-dependent plasma flow and Birkeland currents in the dayside magnetosphere, 2, A global model for northward and southward IMF, J. Geophys. Res., 90, 1595-1609, 1985

Reiff, P. H. and Heelis, R. A.: Four cells or two?: Are four convection cells really necessary, J. Geophys. Res., 99, 3955-3959, 1994.

Rodger, A. S.: Ground-based ionospheric imaging of magnetospheric boundaries, Adv. Space Res., 25, (7/8)1461-1470, 2000.

Rodger, A. S., Coleman, I. J. and Pinnock, M.: Some comments on transient and steady-state reconnection at the dayside magnetopause, Geophys. Res. Lett., 27, 1359-1362, 2000.

Ruohoniemi, J. M. and Baker, K. B.: Large-scale imaging of highlatitude convection with Super Dual Auroral Radar Network HF radar observations, J. Geophys. Res., 103, 20 797-20 811, 1998. 
Ruohoniemi, J. M. and Greenwald, R. A.: Statistical patterns of high-latitude convection obtained from Goose Bay HF radar observations, J. Geophys. Res., 101, 21 743-21 763, 1996.

Russell, C. T.: The configuration of the magnetosphere, in Critical Problems of Magnetospheric Physics, edited by E. R. Dyer, 1-16, Inter-Union Commission on Solar-Terrestrial Physics Secratariat, National Academy of Sciences, Washington, D.C., 1972.

Sandholt, P. E., Farrugia, C. J., Cowley, S. W. H., Lester, M., Denig, W. F., Cerisier, J.-C., Milan, S. E., Moen, J., Trondsen, E., and Lybekk, B.: Dynamic cusp aurora and associated pulsed reverse convection during northward interplanetary magnetic field, J. Geophys. Res., 105, 12 869-12 894, 2000.

Song, P. and Russell, C. T.: Model of the formation of the lowlatitude boundary layer for strongly northward interplanetary magnetic field J. Geophys. Res., 97, 1411-1420, 1992.

Tsyganenko, N. A.: Modelling the Earth's magnetospheric magnetic field confined within a realistic magnetopause, J. Geophys. Res., 100, 5599-5612, 1995.

Tsyganenko, N. A. and Stern, D. P.: Modelling the global magnetic field of large-scale Birkeland current systems, J. Geophys. Res., 101, 27 187-27 198, 1996.
Vasyliunas, V. M.: Steady state aspects of magnetic field line merging, in Magnetic Reconnection in Space and Laboratory Plasmas, Geophys. Monogr. Ser., vol.30, E. W. Hones Jr. (ed.), 25, AGU, Washington, D.C., 1984.

Weimer, D. R.: Models of high-latitude electric potentials derived with a least error fit of spherical harmonic coefficients, J. Geophys. Res., 100, 19595-19607, 1995.

Woch, J. and Lundin, R.: Magnetosheath plasma precipitation in the polar cusp and its control by the interplanetary magnetic field, J. Geophys. Res., 97, 1421-1430, 1992.

Yeoman, T. K., Lester, M., Cowley, S. W. H., Milan, S. E., Moen, J. and Sandholt, P. E.: Simultaneous observations of the cusp in optical, DMSP and HF radar data, Geophys. Res. Lett., 24, 2251-2254, 1997.

Yeoman, T. K., Wright, D. M., Stocker, A. J., and Jones, T. B.: An evaluation of range accuracy in the Super Dual Auroral Radar Network over-the-horizon HF radar systems, Radio Sci., 36, 801-813, 2001. 